\title{
How employees view smart cycling to work: a regional survey in the Netherlands
}

\author{
Tiago Fioreze*, Tom Thomas, Bingyuan Huang, Eric van Berkum \\ Faculty of Engineering Technology, Centre for Transport Studies, University of Twente, \\ P.O. Box 217, 7500 AE, Enschede, The Netherlands
}

\begin{abstract}
The intent of our study is to provide insightful results regarding views and attitudes of employees towards cycling. We were especially interested in their views regarding the use of personalized rewarding schemes delivered via a smartphone app to stimulate cycling to work. The study involved a quantitative on-line survey of employees in Enschede, the Netherlands, and vicinity, wherein 1.800 employees participated. Our results show that most employees commute by bicycle, followed by a considerable percentage who commute (alone) by car. In addition, most employees consider cycling as pleasant, healthy, and refreshing. For employees who often cycle to work, feeling healthy is the most important reason for them to take up cycling. Equally important, the use of apps to stimulate cycling to work has potential, but employees need to be approached accordingly. For example, employees who sometimes cycle to work are more receptive to rewarding schemes delivered via smartphone apps. Conversely, non-cyclists are more reluctant to take up cycling, even if rewards would be offered.
\end{abstract}

Keywords: survey, employees, rewarding schemes, smartphone apps, cycling.

\section{Introduction}

A Dutch person travels, on average, approximately 30 kilometers a day. Commuting to work accounts for about $20 \%$ of the traveling motives, while the remaining $80 \%$ are mostly school commutes, household chores, leisure activities, amongst others [1]. In his turn, a Dutch employee travels, on average, 24 kilometers to and from work a weekday, taking 34 minutes. Approximately $77 \%$ of all commuting kilometers are covered by car (mostly single-occupancy vehicles), $10 \%$ by train and $6 \%$ by bicycle [2].

The research study presented in this paper is part of the European Union's Horizon 2020 EMPOWER project [3], which aims to substantially reduce the use of conventionally fueled vehicles $(\mathrm{CFV})$ in cities and change travel behavior. Adopting a 'reward rather than punishment' approach, EMPOWER explores the use of positive incentives delivered through smartphone technologies to persuade road users to seek more sustainable transport choices.

\footnotetext{
* Corresponding author.

Email address: t.fioreze@utwente.nl (Tiago Fioreze)
} 
While many interventions have already been conducted in order to reduce car use [4] [5], their research methods and outcomes vary widely. Some interventions, nonetheless, have been shown to be effective. For example, it has already been demonstrated that the use of positive incentives, such as rewards and encouragement can stimulate people to reduce car use [6]. Moreover, there is also evidence that people prefer to be 'rewarded rather than punished' [7]. By contrast, according to Olde Kalter [8], 'punishing' car drivers have more impact on bicycle use than cycling promotion measures.

Even though many alternatives to single-occupancy vehicles already exist, we focused our research study on cycling, more specifically on cycling to work. Our research study is part of a micro-experiment that was carried out in Enschede, the Netherlands whose mobility management plan focuses on reducing CFV-mileage by stimulating cycling. Even if the share of trips made by bicycle in Enschede is high in comparison with other European cities (Figure 1), Enschede has seen a considerable drop in bicycle trips in recent years.



Figure 1: The share of trips made by bicycle in some European cities [9].

While, for some people, cycling implies an aspect of healthy living, it also offers a broader range of benefits: reduced congestion, improved air quality, and public health [10]. The physical and mental health benefits of cycling are not only reported by ordinary people but also by health experts [11] [12]. Moreover, besides its popularity in traditional biking countries like the Netherlands, Denmark, and Germany (Figure 2), cycling has been gaining some popularity in North America as well [13] [14]. Finally, even if the Netherlands is often seen as a reference in terms of bicycle use and bicycle policies [15], other countries have been making great efforts to create cycling cities (e.g., Copenhagen [16]).

With all the benefits that cycling brings to the environmental, social and economic sustainability of the communities it serves [17], the question that still remains unanswered is why more people, especially employees, do not take up cycling for their daily commute? To get more insights about this question, this research study focuses on investigating how employees could potentially be nudged towards commuting to work by bicycle by means of 


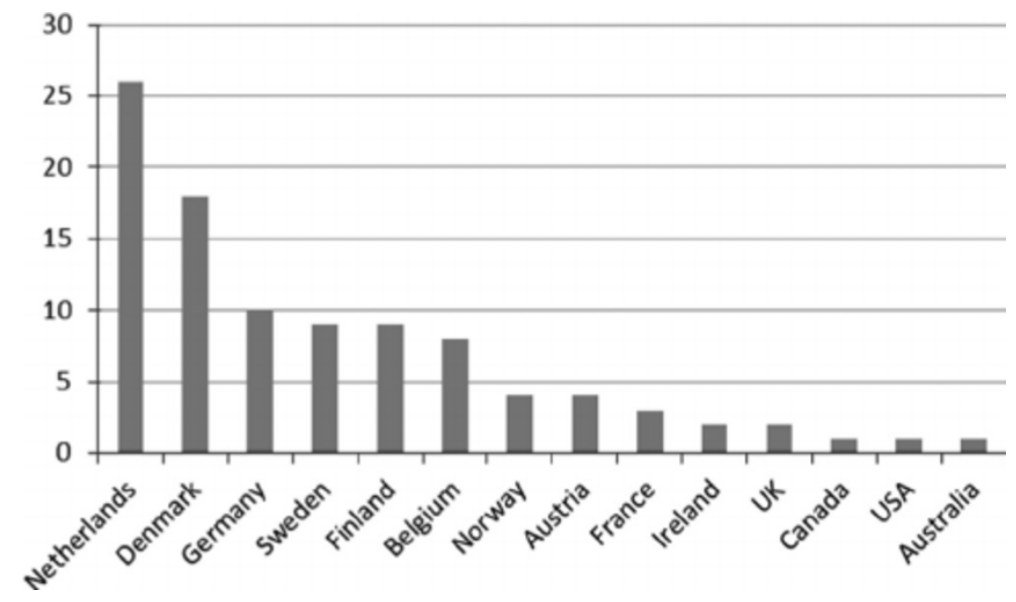

Figure 2: Share of cycling as the percentage of all trips in 14 countries (reprinted from [13]).

positive incentives delivered through smartphone technologies.

All things considered, the aim of our research study was: 1) to quantify the current travel behavior of employees in Enschede and vicinity, 2) to investigate their views and attitudes towards cycling, and 3) to get their feedback on potential rewarding schemes delivered via smartphone apps to stimulate cycling to work.

The remainder of this paper is structured as follows. Section 2 presents how our research study was conducted and how data was analyzed. Following that, Section 3 states the results of the different analyses performed. Finally, we close this paper in Section 4, where we discuss our results and the practical implications of our study. This section also presents the limitations of our research as well as some recommendations for future research directions.

\section{Methods}

In this section, the methodology used to conduct our on-line survey of employees will be presented. Next to this, an overview of the data analysis used in this paper will be provided.

\subsection{Participants}

We sent out emails to employers in Enschede and vicinity in order to invite them to take part in our study. The employers' list was created based on their number of employees, which ranged from a few employees (e.g., 20) to thousands of employees (e.g., 3.500). Of the 54 employers invited, 18 accepted to participate. Of those 18, 10 were a sample of employers located in the city of Enschede (population 160.000), and the remaining 8 were located in 6 municipalities adjacent to Enschede, namely Hengelo (81.000), Hof van Twente (35.000), Dinkelland (26.000), Borne (22.000), Tubbergen (21.000) and Groenlo (10.000).

We then instructed the employers to send an invitation email to their employees explaining the rationale for the study and including a link to our on-line survey. A prize draw was used to stimulate the invited employees to complete the survey. Responses were collected for 5 weeks from September to October 2016. All responses were automatically recorded via the survey platform and downloaded into a comma-separated values (CSV) file. 


\subsection{Questionnaire}

The on-line survey questionnaire was developed after an internal literature review [18] and was implemented on LimeSurvey [19]. The questionnaire consisted of a mix of single choice, multiple choice, ranking ${ }^{1}$, and open-ended types of questions. In addition, 5 interactive mock-ups ${ }^{2}$ were used for the sake of aiding participants to better comprehend how personalized incentives could potentially be delivered via their smartphones. Finally, it took approximately 15 minutes for the participants to complete the questionnaire.

As such, the survey design was a combination of revealed preference (i.e., the actual participants' travel behavior) and stated preference (i.e., the use of hypothetical situations in which mock-ups providing incentives to cycle more were presented to the participants). We used revealed preference for the sake of segmentation and personalization. Regarding the former, we were interested in finding out whether different segments of employees show different attitudes towards cycling as well as towards rewarding schemes that promote cycling. In its turn, the latter was used to provide the correct context for the stated preference part. That is, when the mock-ups were presented to the participants, we wanted to make sure that the context was accurate and the answer options posed to the participants were as realistic and suited to his or her personal situation as possible.

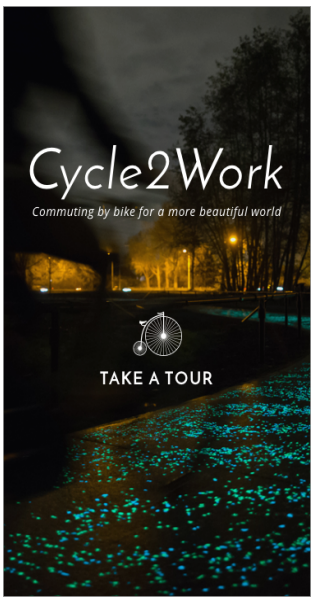

(a) Initial screen



(b) Home screen

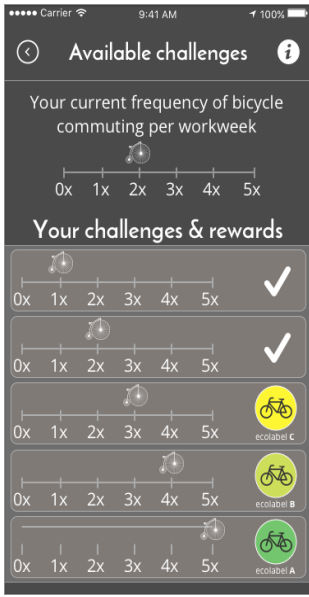

(c) Challenges



(d) Rewards

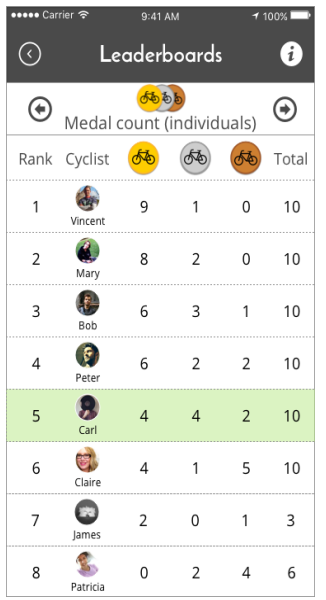

(e) Medal count

Figure 3: Mock-ups screen-shots

Figure 3 shows screen-shots of some of the mock-ups used in our on-line survey. Figure 3a shows the initial screen, wherein the participant is invited to "take a tour" in the mockup. Valuable to note that the mock-up did not represent any actual information about the participant or about his commuting behavior. Following that, a home screen (Figure 3b) presenting some cycling stats is shown. At its lower part, interactive icons were available. Participants could then visualize how challenges might look like (Figure 3c), the number of rewards collected (Figure 3d), and, their position on a fictional leaderboard (Figure 3e).

\footnotetext{
${ }^{1} \mathrm{~A}$ list of possible options was presented to respondents who could then rank them in order of preference.

${ }^{2}$ Representation of a smartphone app containing non-actual commuting behavior and rewarding schemes.
} 
Participants who lived within 20 kilometers away from their workplace and commuted at least 3 times a week to work were selected to interact with the mock-ups. The purpose of these thresholds was to select participants who commute often ( $\geq 3 \mathrm{x}$ a week) from a feasible ${ }^{3}$ cycling distance $(\leq 20 \mathrm{Km})$. They were then randomly assigned to only one of the 5 mock-ups. Each mock-up represented one of the following rewarding schemes:

1. Money: participants' cycling efforts are rewarded with money;

2. In-kind gifts: participants' cycling efforts are rewarded with redeeming points, which can be exchanged for products and/or experiences to their liking;

3. Personal recognition: participants' cycling efforts are acknowledged and appreciated accordingly by means of compliments or badges;

4. Cooperation with others: participants may join their cycling efforts with other cyclists' efforts for the sake of the common good;

5. Competition against others: participants may engage in a friendly competition against other cyclists to motivate one another, with top cyclists eligible for awards.

After interacting with their respective assigned mock-ups, the participants were presented with questions and rewarding schemes personalized to their actual commuting distance and frequency of bicycle commuting. Among other questions, they were asked whether the presented personalized rewarding scheme to be offered via their smartphones would motivate them to either cycle more or keep them always cycling to work.

\subsection{Data analysis}

Data were analyzed with SPSS Statistics (version 24) by using descriptive (Section 3.2) and inferential statistics (Section 3.3) techniques. A statistical approach was based on the distribution of responses. The standard error is given by the standard deviation in the multinomial sample frequency. Some categorical variables (e.g., demographics) were used to create segments (i.e., independent sub-samples). When we compare frequencies of two segments, we only mention statistically significant results, i.e., differences larger than two times the standard error in the difference.

Moreover, since our research interest lies in increasing the frequency of bicycle commuting among employees by means of personalized rewards, we were particularly interested in finding out whether there was any association between the following categorical variables: 1 ) demographics and frequency of bicycle commuting, 2) demographics and rewarding schemes, and 3) frequency of bicycle commuting and rewarding schemes. In order to evaluate whether these categorical variables are related to each other in any way, we used the Chi-square independence test (denoted by $\chi 2$ ). If associated (using a significance level of 0.05), we subsequently employed Cramer's $\mathrm{V}$ (denoted by $\phi_{c}$ ) to quantify how strong the two categorical variables are associated.

\footnotetext{
${ }^{3}$ This threshold is based on the research about distances for bicycle commuting conducted by the Dutch Central Bureau of Statistics [20].
} 


\section{Results}

This section states the results of the different analyses performed. We start by presenting an overview of the participants who took part in our study. Then, we will clarify the descriptive statistics used in the analysis. Finally, the analysis of the correlations between the different categorical variables will be presented and discussed.

\subsection{Participants}

Of the 2.056 employees who logged on to the survey, 1.544 successfully completed it, 256 partially completed it, and 254 did not answer any question (and were discarded). Valuable to note here that partially completed survey entries were considered in our data analysis, only when appropriate. For example, when performing the univariate analysis. However, when performing bivariate analysis, we disregarded incomplete survey entries whose the answer for one of the considered variables was missing.

Consequently, the initial number of participants considered in our data analysis is 1.800 , though this number varies per question on the account that either the answer is missing or the question did not apply to the participant. Lastly, of the 1.800 employees who took part in the on-line survey, $819(45 \%)$ are health professionals, $782(44 \%)$ are public servants, and the remaining 199 (11\%) are industry professionals.

\subsection{Descriptive statistics}

We start by presenting our survey data with summary descriptions of single variables (i.e., univariate analysis). The major characteristics of a single variable that we were interested, were their frequency distribution and their central tendency.

\subsubsection{General travel behavior}

The average one-way commuting distance of the participants is 17 kilometers and less than two-thirds of them $(1.183 / 1.800,65.7 \%)$ take 30 minutes or less to commute to work. The percentage of participants using a particular mode of transport during the standard Dutch workweek (i.e., Monday to Friday) is presented in Figure 4, which shows the combined modal split of all employees as well as segregated by employers ${ }^{4}$. When taking into account all employers combined, the bicycle is the type of transportation mostly used to commute to work $(57 \pm 1 \%)$, followed then by the car $(35 \pm 1 \%)$. The remaining modes account for $8 \pm 1 \%$ of the share. Valuable to note that a similar modal split for UT commuters was found by Geurs et al. [21] who performed a similar travel survey in 2011.

In comparison with the 2015 Dutch Travel Survey [1], in which commuting trips by car is performed by $57 \%$ of participants whereas $24 \%$ by bicycle, the mode choice of our participants is clearly favorable from the perspective of sustainable transport. We think that this difference is rather due to an under-representative selection of employers than a

\footnotetext{
${ }^{4}$ Besides the University of Twente (UT), we also show the modal split of those employers with a representative population in our survey. Due to non-disclosure agreements, we do not disclose the real names of those employers, but we instead represent them by letters (A, B, and so on).
} 


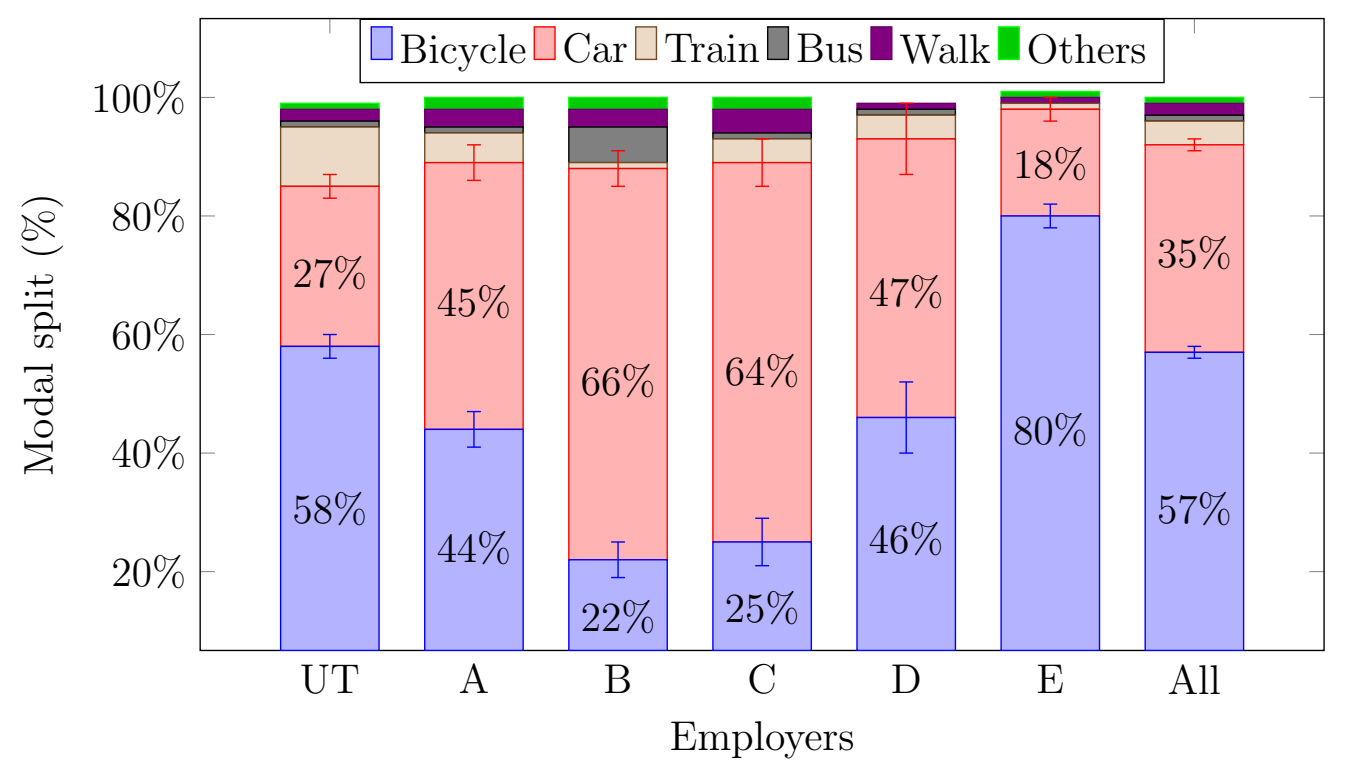

Figure 4: Modal split of commuting trips during the workweek.

response bias by the employees. It is also plausible that our study may have attracted employers whose most of the workforce commute by bicycle.

The average one-way commuting distance is 9 kilometers by bicycle and 21 kilometers by car. Table 1 helps to explain the modal split shown in Figure 4. For example, employer E shows an outstanding percentage $(80 \pm 2 \%)$ of commuters by bicycle, which can be explained by its small average commuting distance $(9 \mathrm{Km})$. More importantly, Employer E informally informed us that they give no access to their car parking space for those employees who live less than 8 kilometers away from work. In the other extreme, employer B has a very low percentage $(22 \pm 3 \%)$ of commuters by bicycle, which can be explained due to its larger average commuting distance $(25 \mathrm{Km})$ and the lack of restrictions for their parking space. Interestingly, employers $\mathrm{C}$ and $\mathrm{D}$ have similar average commuting distances, but employer $\mathrm{C}$ has a bigger percentage of commuters by car. The reported reason for that is that most employees at employer $\mathrm{C}$ need the car for other activities somewhere else during the day.

\begin{tabular}{c|c||c|c|c}
\hline \multirow{2}{*}{ Employer } & \multirow{2}{*}{ \# Participants } & \multicolumn{3}{|c}{ Average commuting distance $(\mathrm{Km})$} \\
\cline { 3 - 5 } & & Overall & By bicycle & By car \\
\hline UT & 433 & 22 & 7 & 25 \\
A & 204 & 17 & 8 & 23 \\
B & 149 & 25 & 9 & 28 \\
C & 121 & 20 & 10 & 23 \\
D & 68 & 19 & 7 & 27 \\
E & 615 & 9 & 9 & 13 \\
All & 1.800 & 17 & 9 & 21 \\
\hline
\end{tabular}

Table 1: Average one-way commuting distance per employer. 


\subsubsection{About the frequency of bicycle commuting}

Participants were asked how many days a workweek they travel to work and how often they use the bicycle as the main mode of transport. Based on those questions, we divided the frequency of bicycle commuting into three categories: always, sometimes and never. Always means a cycling frequency equal to the number of travel days. Whereas never means a cycling frequency equal to zero. Finally, sometimes means a cycling frequency greater than zero and less than the number of travel days. As a side note, a similar segregation is used by Heinen et al. [22]. However, the authors consider a "part-time" commuter (i.e., the equivalent to our sometimes) someone who cycles to work at least once a year. Almost half of our participants $40.9 \%(737 / 1.800)$ stated always to cycle to work whereas $26.1 \%$ (469/1.800) reported sometimes and 33.0\% (594/1.800) as never doing so.

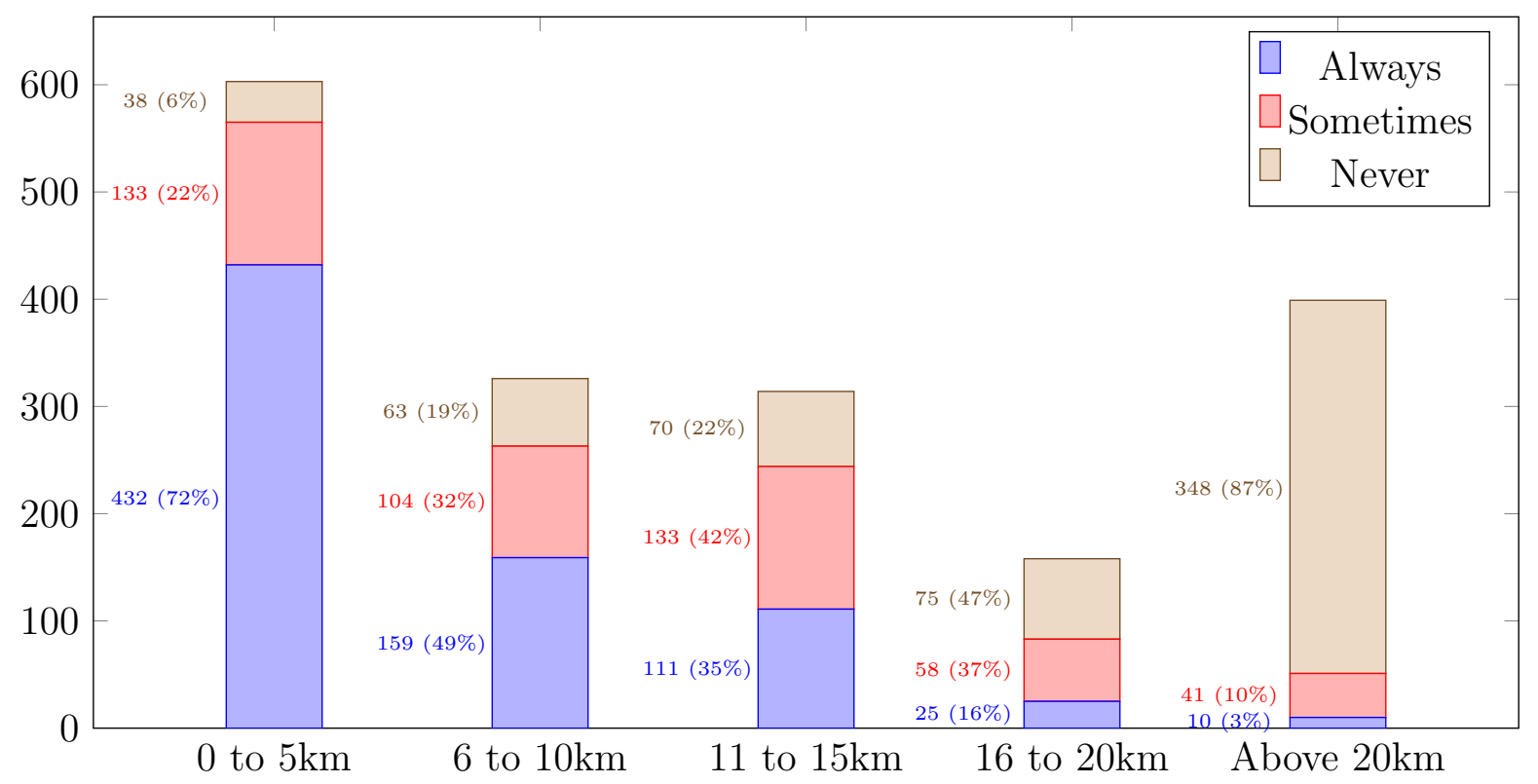

Figure 5: Frequency of bicycle commuting based on ranges of one-way commuting distances $(\mathrm{n}=1.800)$

Commuting distance has a strong influence on cycling frequency as shown in Figure 5. The great majority of participants who live within a distance of 5 kilometers from work (432/603, 72\%) always commute by bicycle. By contrast, the great majority of participants who live more than 20 kilometers away from work $(348 / 399,87 \%)$ never commute by bicycle. Despite the split frequencies for those who live between 6 and 20 kilometers away from work, we still observe a significant percentage of participants who cycle to work. The turning point occurs above 20 kilometers when the percentage of participants who never cycle to work increases considerably. We conclude therefore that one-way distances of up to 20 kilometers are feasible by bicycle for most participants $(1.155 / 1.800,64 \%)$.

\subsubsection{Attitudes and views towards cycling}

Attitudes towards cycling were measured based on the semantic differential technique of Osgood et al. [23]. Employees were asked to rate cycling by means of using a set 
of bipolar statements, each representing a five-point scale (Table 2). In particular, most participants agree that cycling is pleasant, healthy, and refreshing. The same views were observed independently of splitting participants by their frequency of bicycle commuting.

Table 2: Employees' opinions to specific statements about cycling $(n=1.688)$

\begin{tabular}{|c|c|c|c|c|c|c|}
\hline \multicolumn{2}{|c|}{ I find cycling ... } & \multicolumn{5}{|r|}{$\mathrm{n}(\%)$} \\
\hline & & $\begin{array}{l}\text { Strongly } \\
\text { disagree }\end{array}$ & Disagree & Neutral & Agree & $\begin{array}{c}\text { Strongly } \\
\text { agree }\end{array}$ \\
\hline \multirow{4}{*}{... pleasant } & all & $17(1.0)$ & $51(3.0)$ & $184(10.9)$ & $855(50.7)$ & $581(34.4)$ \\
\hline & always & $6(0.8)$ & $9(1.2)$ & $48(6.5)$ & $325(44.3)$ & $346(47.1)$ \\
\hline & sometimes & $5(1.2)$ & $8(1.9)$ & $44(10.5)$ & $222(53.0)$ & $140(33.4)$ \\
\hline & never & $6(1.1)$ & $34(6.4)$ & $92(17.2)$ & $308(57.6)$ & $95(17.8)$ \\
\hline \multirow{4}{*}{... boring } & all & $606(35.9)$ & $690(40.9)$ & $266(15.8)$ & $106(6.3)$ & $20(1.2)$ \\
\hline & always & $330(45.0)$ & $277(37.7)$ & $91(12.4)$ & $31(4.2)$ & $5(0.7)$ \\
\hline & sometimes & $147(35.1)$ & $181(43.2)$ & $63(15.0)$ & $24(5.7)$ & $4(1.0)$ \\
\hline & never & $129(24.1)$ & $232(43.4)$ & $112(20.9)$ & $51(9.5)$ & $11(2.1)$ \\
\hline \multirow{4}{*}{.. healthy } & all & $15(0.9)$ & $11(0.7)$ & $36(2.1)$ & $640(37.9)$ & $986(58.4)$ \\
\hline & always & $4(0.5)$ & $3(0.4)$ & $10(1.4)$ & $234(31.9)$ & $483(65.8)$ \\
\hline & sometimes & $6(1.4)$ & $2(0.5)$ & $6(1.4)$ & $159(37.9)$ & $246(58.7)$ \\
\hline & never & $5(0.9)$ & $6(1.1)$ & $20(3.7)$ & $247(46.2)$ & $257(48.0)$ \\
\hline \multirow{4}{*}{... stressful } & all & $918(54.4)$ & $622(36.8)$ & $112(6.6)$ & $28(1.7)$ & $8(0.5)$ \\
\hline & always & $475(64.7)$ & $222(30.2)$ & $27(3.7)$ & $7(1.0)$ & $3(0.4)$ \\
\hline & sometimes & $217(51.8)$ & $168(40.1)$ & $25(6.0)$ & $6(1.4)$ & $3(0.7)$ \\
\hline & never & $226(42.2)$ & $232(43.4)$ & $60(11.2)$ & $15(2.8)$ & $2(0.4)$ \\
\hline \multirow{4}{*}{... refreshing } & all & $15(0.9)$ & $42(2.5)$ & $178(10.5)$ & $867(51.4)$ & $586(34.7)$ \\
\hline & always & $4(0.5)$ & $8(1.1)$ & $49(6.7)$ & $335(45.6)$ & $338(46.0)$ \\
\hline & sometimes & $6(1.4)$ & $10(2.4)$ & $36(8.6)$ & $222(53.0)$ & $145(34.6)$ \\
\hline & never & $5(0.9)$ & $24(4.5)$ & $93(17.4)$ & $310(57.9)$ & $103(19.3)$ \\
\hline \multirow{4}{*}{... exhausting } & all & $382(22.6)$ & $693(41.1)$ & $410(24.3)$ & $181(10.7)$ & $22(1.3)$ \\
\hline & always & $248(33.8)$ & 307 (41.8) & $128(17.4)$ & $46(6.3)$ & $5(0.7)$ \\
\hline & sometimes & $77(18.4)$ & $172(41.1)$ & $117(27.9)$ & 49 (11.7) & $4(1.0)$ \\
\hline & never & $57(10.7)$ & $214(40.0)$ & $165(30.8)$ & $86(16.1)$ & $13(2.4)$ \\
\hline
\end{tabular}

We were also interested in the participants' opinion regarding their current travel behavior. When asked to rank a set of statements (Figure 6), participants chose "I want to save travel time" as the most important reason for choosing a specific mean of transport. However, when splitting participants by their frequency of bicycle commuting, we observe that those who always or sometimes cycle to work find the statement "I want to feel healthy" as the most important one ( $30 \pm 2 \%$ and $28 \pm 2 \%$, respectively), whereas this reason was only mentioned by $4 \pm 1 \%$ of the respondents who never cycle. Respondents who never cycle mostly chose the statement "I want to save travel time". Not only travel time, but also convenience is an important reason for them. With regard to employees who sometimes or 
always cycle, there are few statistically significant differences. The exception is that employees who always cycle are more concerned about the environment $(11 \pm 1 \%$ versus $7 \pm 1 \%$ for the occasional cyclists), while employees who sometimes cycle find safety more important ( $5 \pm 1 \%$ versus $1 \pm 1 \%$ for the always group).

\section{I want to ...}



Figure 6: Employees' ranking to statements regarding mode choice $(\mathrm{n}=1.795)$

Finally, we were interested in knowing how often participants talk with others about cycling in relation to environmental protection and health. Half of the participants $(842 / 1.689$, $49.9 \%)$ reported to never or rarely doing so, whereas less than half $(689 / 1.689,40.7 \%)$ reported doing that sometimes. Only a small percentage $(158 / 1.689,9.4 \%)$ stated to do that often or always.

\subsubsection{Reasons for cycling to work and the influence of different weather conditions}

Concerning participants who cycle at least once a week to work, they were asked to select a maximum of 3 reasons for doing so. An overwhelming majority of cyclists $(987 / 1.206$, $81.8 \%$ ) said that cycling makes them feel healthier / fitter. Next, less than half $(558 / 1.206$, $46.3 \%$ ) reported that cycling is the cheapest mode of transport. Finally, there are also concerns with respect to the environment. Over one-third $(485 / 1.206,40.2 \%)$ cycles to work due to environmental friendliness.

In contrast, participants who not always cycle to work declared that unpleasant weather conditions (e.g., rain or wind) are major deterrents $(565 / 1.063,53.2 \%)$. Likewise, long journey times $(385 / 1.063,36.2 \%)$ and large distances $(380 / 1.063,35.7 \%)$ were also chosen as reasons for not cycling to work. Incidentally, when segregating those 1.063 respondents into commuters who never and sometimes cycle to work, the reasons for not cycling to work differ significantly. Of those who sometimes cycle to work, $82.0 \%$ declared unpleasant weather conditions as being the biggest deterrent for them to cycle more. In their turn, of those who never cycle to work, $58.7 \%$ stated that their commuting distance is too far to cycle while $52.8 \%$ stated that the journey time by bicycle is too long. 


\begin{tabular}{c|ccccc}
\hline \multirow{2}{*}{ Weather conditions } & Never & Seldom & Sometimes & Often & Always \\
\hline Daylight, $0^{\circ} \mathrm{C}$, rainy & $111(9.7)$ & $168(14.6)$ & $230(20.0)$ & $168(14.6)$ & $472(41.1)$ \\
\hline Daylight, $0^{\circ} \mathrm{C}$, sunny & $6(0.5)$ & $21(1.8)$ & $168(14.6)$ & $213(18.5)$ & $741(64.5)$ \\
\hline Daylight, $0^{\circ} \mathrm{C}$, windy & $34(3.0)$ & $59(5.1)$ & $203(17.7)$ & $209(18.2)$ & $644(56.0)$ \\
\hline Darkness, $0^{\circ} \mathrm{C}$, clear sky & $34(3.0)$ & $63(5.5)$ & $182(15.8)$ & $211(18.4)$ & $659(57.04)$ \\
\hline Daylight, $15^{\circ} \mathrm{C}$, rainy & $80(7.0)$ & $135(11.7)$ & $263(22.9)$ & $178(15.5)$ & $493(42.9)$ \\
\hline Daylight, $15^{\circ} \mathrm{C}$, sunny & $0(0.0)$ & $8(0.7)$ & $90(7.8)$ & $254(22.1)$ & $797(69.4)$ \\
\hline
\end{tabular}

Table 3: Cyclists' likelihood to cycle under certain weather conditions $(n=1.149)$

Since unpleasant weather conditions are a major deterrent for cycling to work, participants who cycle at least once a week to work were also invited to express how likely they would cycle under certain weather conditions (Table 3). Rainy conditions considerably reduce the participants' willingness to cycle to work. When under rainy conditions, we observe a reduction of approximately $40 \%$ in the number of participants who reported to always cycle. Lower temperatures, windy conditions and darkness also play a role, but the reduction is rather small (about 11\%).

\subsubsection{On the use of smartphone applications (apps) for stimulating cycling}

Despite the very high $(1.628 / 1.686,96.6 \%)$ use of smartphones in general, the use of apps for cycling purposes is low. Over one-quarter $(457 / 1.695,26.9 \%)$ stated to use an app for motivating them to cycle (e.g., Strava). Conversely, the use of apps for general travel plans is more common (1.104/1.695, 65.1\%), being Google Maps mostly used (696/1.695, 41.1\%). Further, segregating participants by their frequency of bicycle commuting did not render significant differences, except that participants who always or sometimes cycle tend to use more weather-related apps than those who never cycle.

Would this rewarding scheme motivate you to cycle (more) to work?

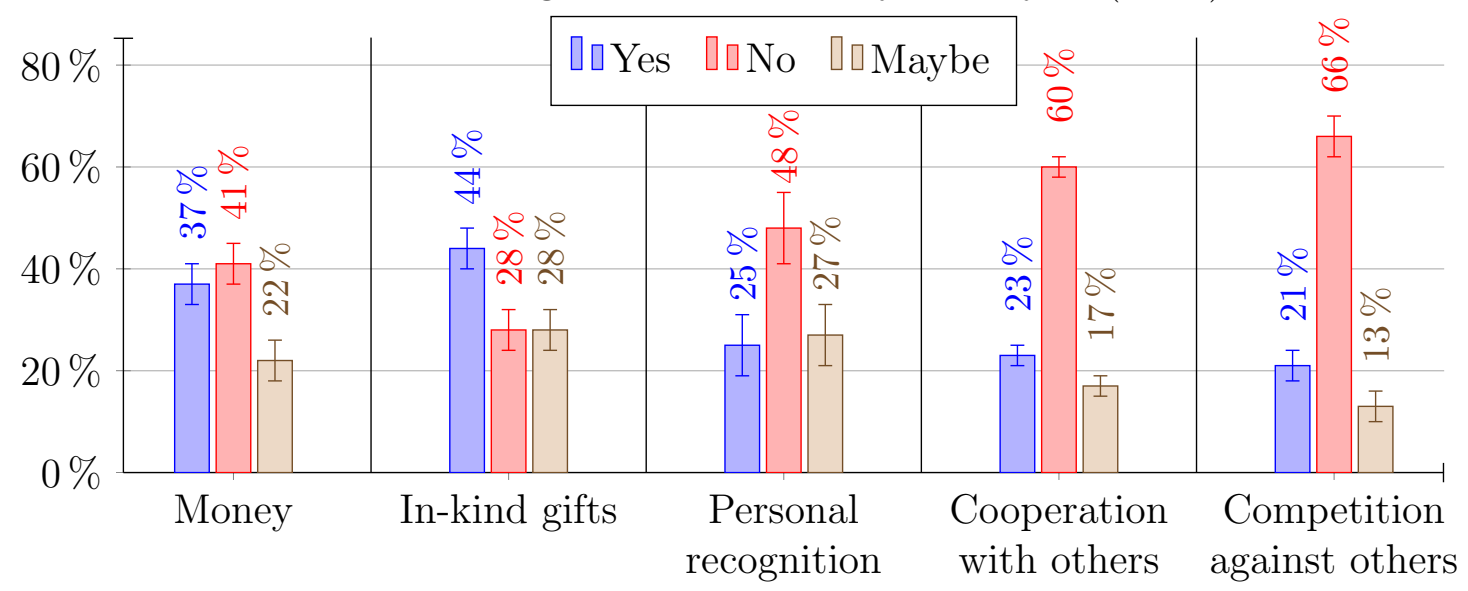

Figure 7: Stated preference regarding rewarding schemes $(\mathrm{n}=1.151)$ 
Shortly after having interacted with one of the 5 mock-ups, participants who lived within 20 kilometers away from their workplace and commuted at least 3 times a week to work were asked whether the rewarding scheme offered to them would motivate them to cycle (more) to work (Figure 7). Most of the participants who interacted with the in-kind gifts mock-up declared to feel motivated by it. However, it is here unclear to us whether the participants disliked (or liked) a certain rewarding scheme because they do not like the rewarding scheme, in the first place, or because they did not like the mock-up itself (e.g., its design).

The same set of participants were then subsequently informed that they had been introduced to one rewarding scheme, but that there were other rewarding schemes being taken into consideration in our study. We then posed the following question: "Which kind of rewarding scheme would motivate you the most to cycle to work?". Figure 8 shows that the participants would still most likely choose for rewarding schemes with tangible rewards $(757 / 1.151,65 \%)$. However, most of them $35 \pm 1 \%$ (408/1.151) would prefer money this time and $30 \pm 1 \%$ (349/1.151) would prefer in-kind gifts. Only $2 \%(18 / 1.151)$ would feel motivated to cycle to work by means of a personal recognition. Reward schemes based on gamification [24] seem to not be very attractive either. A small percentage $(71 / 1.151,6 \%)$ chose either "Cooperation with others" or "Competition against others". A considerable amount $(264 / 1.151,23 \pm 1 \%)$ of participants would rather not be rewarded at all. At last, some participants $(41 / 1.151,4 \pm 1 \%)$ have suggested other types of rewards (e.g., health gain).

Which kind of rewarding scheme would motivate you the most to cycle to work?

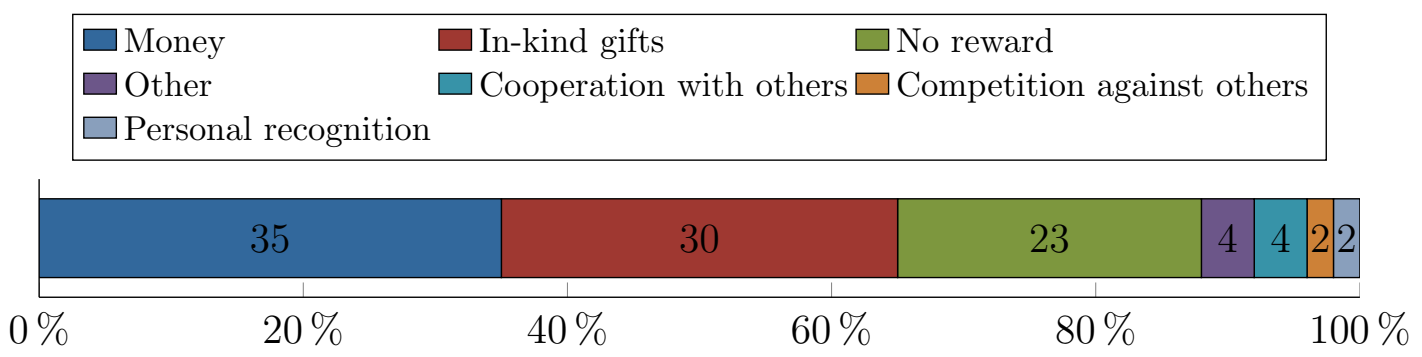

Figure 8: Frequency distribution of preferred rewarding scheme $(n=1.151)$

Valuable to note that most participants who have interacted with a certain rewarding scheme changed their mind afterward. We observed that most of the participants $(233 / 318$, $73.2 \%$ ) who answered "Yes" to the question shown in Figure 7, chose another rewarding scheme when offered to do so (Figure 8). Most of them chose money for a reward, followed closely by the in-kind gifts rewarding scheme. Interesting enough, most of the participants who chose money in the first place, stuck to their choice afterward.

\subsubsection{On tracking whereabouts, unexpected rewards, and unequal rewarding schemes}

Equally relevant, when informed that we were developing an app that needs to track their bicycle commutes to reward them accordingly, and asked whether that is a problem, $59.1 \%(679 / 1.149)$ said that is not a problem, whereas $22.7 \%(261 / 1.149)$ think otherwise. The remaining $18.2 \%$ (209/1.149) were unsure. We have noticed, although, that participants 
who never cycle are slightly more reluctant to be tracked: $32.6 \%(56 / 172)$ of them think that is a problem, whereas $45.9 \%(79 / 172)$ think otherwise.

Furthermore, those participants who always commute by bicycle were also asked whether unexpected rewards for always cycling to work would help them to maintain their frequency of bicycle commuting. Over half $(314 / 603,52.1 \%)$ said that it would not influence their cycling behavior at all. Conversely, less than half $(289 / 603,47.9 \%)$ said it would motivate them to always keep cycling. The latter was also asked what they would rather get a special treat. The great majority $(229 / 289,79.2 \%)$ prefers the certainty of a small gift (e.g., a movie ticket) instead of the probability of a big gift (e.g., an e-bike).

Last but not least, we also asked them whether men and women should be differently rewarded. For that, we have created a fictitious hypothesis stating that with the same level of physical effort, there was about a $20 \%$ difference between male and female performance. A female cyclist would, therefore, get an extra $20 \%$ reward over what is offered to a male cyclist (for the same effort). Participants were then asked if they think that is fair. Quite interestingly, men and women answered this question very similarly. A three-quarter majority $75.6 \%(861 / 1.139)$ of both men and women believe this special treatment is unfair.

\subsection{Inferential statistics}

We present now some bivariate analysis of our results, wherein we seek to find any association between some categorical variables.

\subsubsection{Demographics versus frequency of bicycle commuting}

We analyze here whether demographic factors are associated with frequency of bicycle commuting. The demographic factors considered were: gender, age, education level, household composition and monthly gross income.

In general, the demographics of the participants were similar to that of the Statistics Netherlands (CBS) database [25], although a larger than expected proportion of participants (69.2\% vs 35.5\%) were highly educated (i.e., academic degree). Individuals with medium (i.e., secondary education) and low (i.e., primary education) levels of education were underrepresented: (26.9\% vs $42.1 \%$ ) and (4.0\% vs $21.4 \%$ ), respectively. A very weak level of association between demographics and frequency of bicycle commuting was observed, as summarized in Table 4.

\begin{tabular}{|c||c|c|}
\hline Association of interest & Chi-square independence test & Cramer's $V$ \\
\hline Frequency and Gender & $\chi^{2}(2)=9.94, \mathrm{p}=0.007$ & $\phi_{c}=0.080$ \\
\hline Frequency and Age & $\chi^{2}(6)=43.11, \mathrm{p}=0.000$ & $\phi_{c}=0.118$ \\
\hline Frequency and Education level & $\chi^{2}(4)=10.07, \mathrm{p}=0.039$ & $\phi_{c}=0.057$ \\
\hline Frequency and Household composition & $\chi^{2}(8)=8.37, \mathrm{p}=0.398$ & $\mathrm{n} / \mathrm{a}$ \\
\hline Frequency and Monthly gross income & $\chi^{2}(6)=21.86, \mathrm{p}=0.001$ & $\phi_{c}=0.095$ \\
\hline
\end{tabular}

Table 4: Association summary between demographics and frequency of bicycle commuting.

We highlight the contingency table between the categorical variables age and frequency of cycling (see Figure 9). Valuable to note that young adults (ages 19-44 years) are more 
likely to never cycle to work. In contrast, older individuals (ages $\geq 45$ years) are more likely to always cycle to work.

\begin{tabular}{|c|c|c|c|c|c|c|c|c|c|c|c|}
\hline & & \multicolumn{8}{|c|}{ Age ranges } & \multirow{2}{*}{\multicolumn{2}{|c|}{ Total }} \\
\hline & & \multicolumn{2}{|c|}{19 to 34} & \multicolumn{2}{|c|}{35 to 44} & \multicolumn{2}{|c|}{45 to 54} & \multicolumn{2}{|c|}{55 or older } & & \\
\hline & & Count & $\begin{array}{l}\% \text { within } \\
\text { Cycling } \\
\text { frequency }\end{array}$ & Count & $\begin{array}{l}\% \text { within } \\
\text { Cycling } \\
\text { frequency }\end{array}$ & Count & $\begin{array}{l}\% \text { within } \\
\text { Cycling } \\
\text { frequency }\end{array}$ & Count & $\begin{array}{l}\% \text { within } \\
\text { Cycling } \\
\text { frequency }\end{array}$ & Count & $\begin{array}{l}\% \text { within } \\
\text { Cycling } \\
\text { frequency }\end{array}$ \\
\hline \multirow[t]{3}{*}{ Cycling frequency } & Always & 152 & $24.1 \%$ & 116 & $18.4 \%$ & 216 & $34.2 \%$ & 148 & $23.4 \%$ & 632 & $100.0 \%$ \\
\hline & Never & 153 & $29.3 \%$ & 149 & $28.5 \%$ & 148 & $28.4 \%$ & 72 & $13.8 \%$ & 522 & $100.0 \%$ \\
\hline & Sometimes & 78 & $19.7 \%$ & 100 & $25.3 \%$ & 119 & $30.1 \%$ & 99 & $25.0 \%$ & 396 & $100.0 \%$ \\
\hline Total & & 383 & $24.7 \%$ & 365 & $23.5 \%$ & 483 & $31.2 \%$ & 319 & $20.6 \%$ & 1550 & $100.0 \%$ \\
\hline
\end{tabular}

Figure 9: Crosstab between age and frequency of cycling: $\chi^{2}(6)=43.11, \mathrm{p}=0.000$ and $\phi_{c}=0.118$

We also observed that males are more likely to never cycle to work whereas females are more likely to cycle sometimes, which is similarly reported by the Dutch Central Bureau of Statistics [2]. Moreover, individuals with higher-income levels $(\geq € 3.000)$ are more likely to never cycle to work. In contrast, individuals with lower income levels $(\leq € 2.999)$ are more likely to always cycle to work.

\subsubsection{Demographics versus preferred rewarding scheme}

Following, we sought to find out whether demographic factors are somehow associated with the offered rewarding schemes in our study. We observed a very weak level of association between them, as summarized in Table 5 .

\begin{tabular}{|c||c|c|}
\hline Association of interest & Chi-square independence test & Cramer's V \\
\hline Rewards and Gender & $\chi^{2}(6)=22.57, \mathrm{p}=0.001$ & $\phi_{c}=0.141$ \\
\hline Rewards and Age & $\chi^{2}(18)=55.34, \mathrm{p}=0.000$ & $\phi_{c}=0.127$ \\
\hline Rewards and Education level & $\chi^{2}(6)=13.69, \mathrm{p}=0.033$ & $\phi_{c}=0.078$ \\
\hline Rewards and Household composition & $\chi^{2}(12)=18.46, \mathrm{p}=0.102$ & $\mathrm{n} / \mathrm{a}$ \\
\hline Rewards and Monthly gross income & $\chi^{2}(9)=27.61, \mathrm{p}=0.001$ & $\phi_{c}=0.102$ \\
\hline
\end{tabular}

Table 5: Association summary between demographics and rewarding scheme.

A clear distinction between male and female's preferences for rewarding schemes is highlighted in Figure 10. Males are more likely to prefer rewarding schemes in which competition against others and/or money are involved. They are also likely to not want any reward. Conversely, females are more likely to prefer that their cycling efforts are acknowledged and appreciated accordingly by means of personal recognition (e.g., compliments or badges). They are also more likely to prefer in-kind gifts over money. Interestingly enough, they are also very likely to prefer something else than what was offered to them.

Very weak levels of association between age and monthly income levels with preferred rewarding scheme were also observed. Young adults (ages 19-44 years) are more likely to choose competition against others. Middle-aged adults (ages 45-54 years) prefer something else than what it was offered to them. Finally, older adults (aged older than 55 years) are more likely to either not want any reward or choose cooperation with others. Regarding 


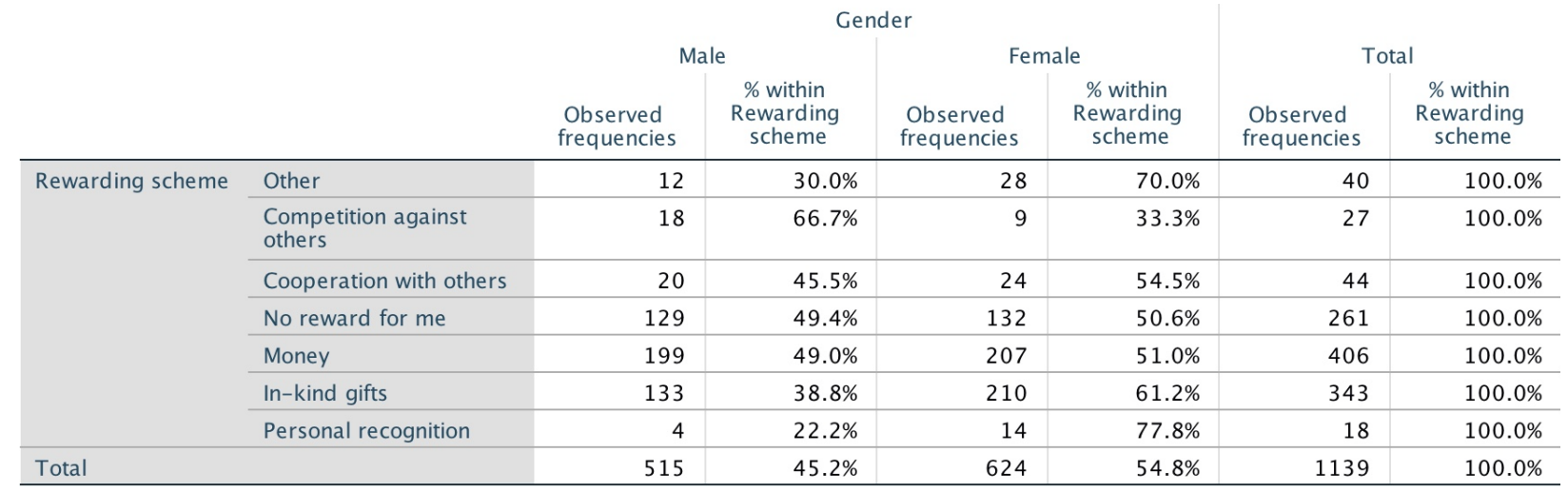

Figure 10: Crosstab between gender and rewarding scheme: $\chi^{2}(6)=22.57, \mathrm{p}=0.001$ and $\phi_{c}=0.141$

monthly income levels, low-income individuals (€1.999 or less) prefer money as a reward. Lower-middle-income individuals $(€ 2.000$ - $€ 2.999)$ are more likely to choose in-kind gifts or other types of reward. Finally, individuals with a monthly income higher than $€ 3.000$ are more likely to not want any kind of reward.

\subsubsection{The frequency of bicycle commuting versus preferred rewarding scheme}

Finally, we sought to find out whether the frequency of bicycle commuting is associated with the considered rewarding schemes in our study. We observed a weak level of association between these two categorical variables: $\chi^{2}(12)=54.18, \mathrm{p}=0.000$ and $\phi_{c}=0.153$.

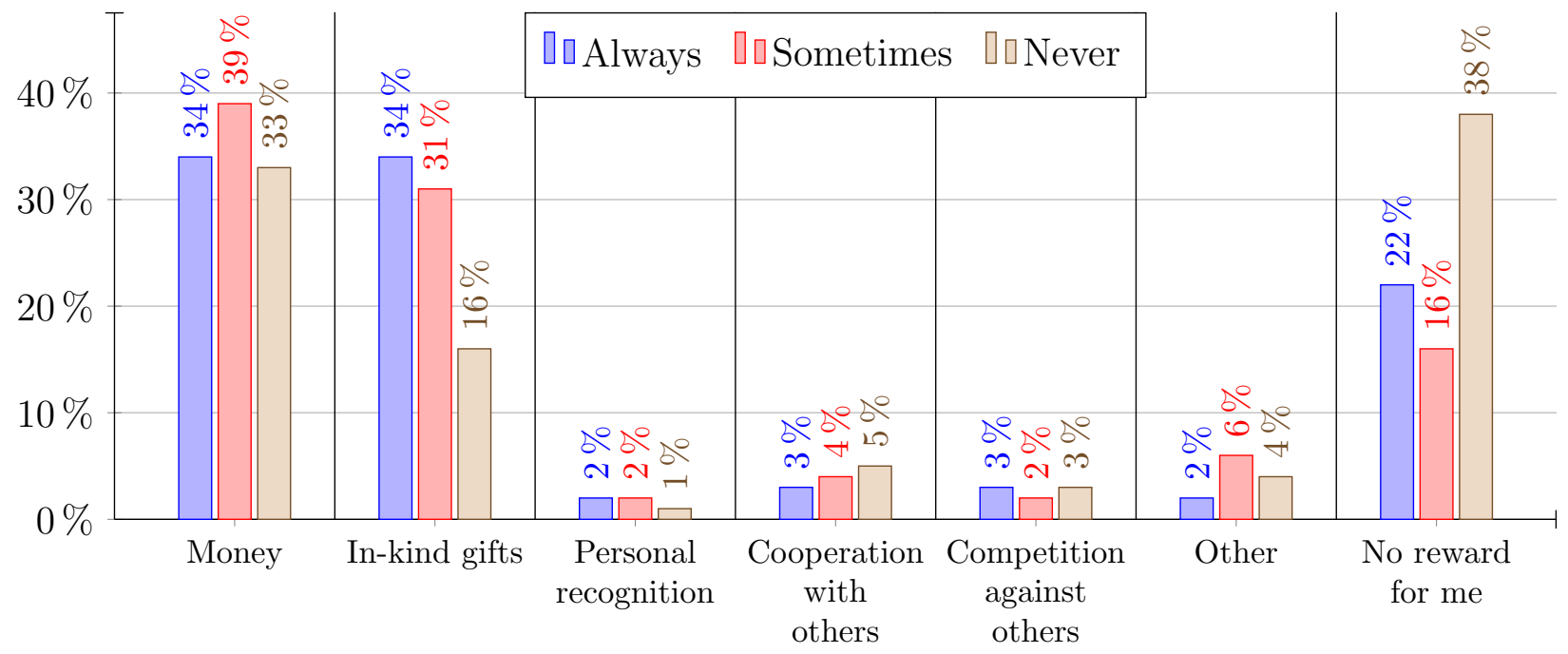

Figure 11: Preferred rewarding scheme based on the frequency of cycling $(n=1.151)$

As seen in Figure 11, participants who sometimes cycle to work are slightly more willing to be rewarded with tangible rewards $(70 \%)$ than participants who always cycle $(68 \%)$. On the other hand, about half $(49 \%)$ of participants who never cycle would choose a tangible 
reward scheme to motivate them to start cycling to work. Moreover, a considerable amount of them $(38 \%)$ reported not to be interested in any rewarding scheme.

We conclude here that employees who sometimes cycle to work are more receptive to rewarding schemes. They are the ideal target for campaigns that envisages to increase the frequency of bicycle commuting. Non-cyclists, on the other hand, are more reluctant to give away the convenience and comfort of their cars. Therefore, the sole use of rewards for stimulating bicycle commuting without any external intervention to use the car less may be potentially inefficient against avid car users.

\section{Discussion}

\section{The frequency of bicycle commuting could potentially be increased at medium distances}

Our results seem to indicate that bicycle commuting is largely popular among employees in Enschede and vicinity for commuting distances below 20 kilometers. We observed high rates of bicycle use (64\%) among participants who live less or equal to 20 kilometers away from work. Above that distance, other means of transportation, especially cars, become the preferred choice for most participants (59\%).

Moreover, our distance decay (see Figure 5), which shows the employees' willingness to travel a certain distance to get to work, is smaller when compared to the National Travel Survey data from the Dutch Central Bureau of Statistics (CBS) [20]. According to the CBS, the average individual will mostly cycle under $7.5 \mathrm{Km}$ each day. Conversely, for cycling distances beyond $15 \mathrm{Km}$, there are almost no cycling trips (about $1 \%$ of the modal split) performed. However, our results suggest that cycling is still very popular up to $15 \mathrm{Km}$ and that even beyond $15 \mathrm{Km}(16-20 \mathrm{Km})$ the fraction of cyclists is still significant. Partly, these results could be attributed to the fact that the participating employers do probably not form a representative sample. However, these results are partly caused by the fact that, in contrast with most studies, we categorize trip-makers rather than trips.

Similarly, even though most trips are not made by bike between 16 - $20 \mathrm{Km}$, a considerable amount of respondents sporadically use the bike for commuting those distances. In fact, between 6 and $20 \mathrm{Km}$, which are medium distances not necessarily associated with cycling, we observed a high percentage of (occasional) cyclists. Given that occasional cyclists are more receptive to rewarding schemes that stimulate cycling to work, we believe, therefore, that there is some potential for improving the frequency of cycling at those distances. Equally relevant, with the increasing popularity of electric bicycles (i.e., e-bikes) [2], one might argue that cycling longer commuting distances could potentially be possible.

Finally, most participants appreciate bicycle commuting when conditions are just right. That is when it is not raining and temperatures are pleasant. Solving the problem of cycling under unpleasant weather conditions is a harder task to tackle, which requires further investigation. One might wonder whether occasional cyclists who are more receptive to positive incentives to stimulate cycling would also feel motivated by those incentives when cycling under bad weather conditions. 


\section{Feeling healthy is an important reason to cycle to work}

The great majority of participants have reported positive views towards cycling to work. They consider cycling as being pleasant, healthy, and refreshing. Some participants cared to elaborate by stating that cycling makes them feel good not only physically, but also mentally. "A perfect moment to clear my head on a daily basis", as declared by one participant.

With respect to the main reasons for cycling to work, health, the environment, and costsaving are the main reasons for participants to commute by bicycle. Even though health is not explicitly included in traditional traffic models, results from this study show that health benefits are important reasons for cycling to work: $82 \%$ of the participants who cycle at least once a week to work said that cycling makes them feel healthier / fitter.

Several studies have shown that cycling has a positive effect on health [26] [27] [28], and that cycling to work may be a feasible way to achieve the half-hour of activity per day as commonly recommended [29]. However, while many existing bicycle studies focus on identifying built environment factors that affect the bicycle use [30] [31], to the authors' knowledge, very little research has yet been conducted on how positive health benefits may be a factor in influencing commuters to cycle to work [32]. In particular, even though our study focused on employing extrinsic rewards (e.g., money) for stimulating commuting to work by bike; based on the results here presented, the authors believe that health benefits could potentially be used as a powerful intrinsic reward to persuade car drivers to choose the bicycle over the car.

At last, even if most participants consider health and environmental aspects as important reasons for cycling, we have observed that half of them rarely or never talk to others about cycling in relation to environmental protection and health. One may wonder whether that is due to common knowledge.

\section{Personal incentives via smartphone apps to cycle to work have potential}

Participants who sometimes cycle to work are more positive about using apps to cycle to work than participants who never do so. Occasional cyclists seem to be the best target group for the introduction of rewarding schemes delivered via smartphone apps, thus. For non-cyclists, by contrast, rewarding schemes are probably not enough to encourage cycling, but should ideally be supported with campaigns that stimulate them to consider cycling.

With respect to rewarding schemes, they should be personalized to particular groups. Males are more likely to prefer money as a reward or willing to engage in a friendly competition against other cyclists, wherein top cyclists are eligible for awards. They are also more likely to not want any kind of reward. Females, on the other hand, are more likely to prefer in-kind gifts or something (a badge, for instance) that acknowledges their cycling efforts. Finally, the richer or older one is, the bigger the chances are that they are not interested in any kind of reward. Older people, although, are more likely to engage in joining (i.e., cooperating with) other cyclists efforts for the sake of the common good.

All things considered, tangible rewards seem to be the favorite rewarding scheme among employees, but results are not conclusive regarding which type of tangible reward works the best. According to some studies, in-kind gifts can be a good alternative to money [33] [34]. However, Shaffer and Arkes [35] concluded that this is only the case when money and in-kind 
gifts are not offered simultaneously. Moreover, asking people to rate which rewarding scheme would motivate them to cycle the most, does not necessarily mean that rewarding scheme is the most effective. In other words, people's lay intuitions about what might motivate them to do something does not necessarily translate in that being the most influential, as previously observed in other studies [36] [37]. In order to circumvent this shortcoming, we believe that after a set of rewarding schemes is considered, they must be field tested to determine how they are actually perceived by participants.

Finally, it is worth highlighting that most participants do not use smartphone apps for cycling purposes only. Smartphone apps are mostly used for general travel plans, independent of being by bicycle or not. That fact could hamper policies that envision introducing incentives to cycle to work delivered via smartphone technologies.

\section{Tracking whereabouts is not a problem, neither is gender inequality}

Many employees are not concerned about having their whereabouts tracked in order to be rewarded for good mobility behavior. Six in ten employees do not find that problematic. Many of them explicitly say that privacy is a must, though. They want to be the owner of their mobility data, which may not be used for any other purpose without their consent.

As a side research, we were happily surprised to find out that gender inequality is not an issue regarding incentives to cycle to work. Participants strongly believe that rewarding cycling efforts should not be discriminated based on gender, given that cycling is a matter of choice and that the physical effort is only a consequence of that decision. Both men and women should, therefore, be equally stimulated when it comes to bicycle commuting.

\section{Limitations of the research}

The findings of our study might be biased. It is possible that our research study may not have attracted a representative subset of employers and, as a result of that, we may have elicited responses from employers whose workforce is mostly interested in green commuting, potentially biasing our sample. For instance, employers that invest in bicycle-friendly policies and/or employees who are open to commuting by bicycle may yield much higher cycling rates than average employers. This potential bias is likely to be due to the under-representation of employers in Enschede and vicinity. While we had few participants from the industrial sector, we had many participants from the health and public sectors. Plus, we observed a higher participation (than the national average) of employees with high levels of education. Employees with low and medium levels of education were underrepresented, thus. Valuable to note, however, that a range of different employers was invited to take part in our study, but most of them declined the invitation. We suspect that studies as such tend to attract employers whose workforce are more highly educated and environmentally friendly. All things considered, the findings presented in this study might be biased towards the positive aspects of using bicycles for commuting to work and should be, therefore, cautiously taken into consideration. 


\section{Future directions}

This research study reveals three key areas where further research could be directed. First, our results show that health is one of the most important reasons for cycling to work. The health benefits of actively commuting to work must be better highlighted, though. This requires, therefore, an expanded investigation of the concrete benefits in the subjects' physical and psychological well-being when cycling (and/or walking) to work instead of taking the car. Our hypothesis is that car drivers will tend to use the car less, once they have the first-hand experience of the health benefits related to actively commuting to work.

Second, in order to get (more) people in cities to actively commute to work, one could think in the combination of reward and punishment approaches, instead of using them as mutually exclusive policy measures. One could think of employing here a hybrid approach, wherein a commuter is either rewarded when he uses active modes of transport or punished when he uses the car, namely a "carrot or stick approach". By employing this approach, we expect that car users will move towards active transports because of the rewards offered, while also moving away from their status quo since they do not want to be punished. By the same token, active users are expected to remain motivated due to the rewards offered, while avoiding the punishment by driving a car.

At last, our results show that the frequency of bicycle commuting for cycling distances beyond $15 \mathrm{Km}$ is still quite significant. Since we did not distinguish between the use of regular or electric bicycles in our study, one might wonder whether this significant frequency was not due to the use of e-bikes among some of our respondents. If so, an interesting future research would be to find out whether e-bikes could revolutionize long-distance commuting. For example, by analyzing how much further the distances covered by e-bikes are when compared to regular bicycles.

\section{Conclusion}

Our study is a comprehensive analysis of current traffic behavior by employees in Enschede and vicinity. It underlines the continuing need to stimulate active commuting modes, which seem to have a wide acceptance among employees in the region. Nonetheless, our study shows a rather unsurprising reluctance of avid car users, unlike to the willingness of occasional cyclists, in engaging with the use of positive incentives (delivered via smartphone technologies) to cycle to work. Finally, the results presented here might help to formulate better sustainable transport strategies, bringing the use of active modes to a better light as sustainable commuting becomes more and more important in the field of transportation.

\section{Acknowledgments}

This study was supported by the European project EMPOWER with funding from the European Union's Horizon 2020 research and innovation programme under grant agreement No 636249. This study has also benefited from the collaboration with other EMPOWER partners. Special thanks to Karel Kroeze for his help in conducting the on-line survey. 


\section{References}

[1] Dutch Central Bureau of Statistics, Onderzoek Verplaatsingen in Nederland 2015. (Dutch) [Research on Transportation in the Netherlands], [Online; accessed March 22, 2018] (2015).

URL https://www.cbs.nl/-/media/_pdf/2016/38/2016ep27.pdf

[2] Dutch Central Bureau of Statistics, Transport and Mobility Statistics Netherlands, [Online; accessed March 22, 2018] (2016).

URL https://www.cbs.nl/en-gb/publication/2016/25/transport-and-mobility-2016

[3] EMPOWER, EMPOWER: rewarding change, [Online; accessed March 22, 2018] (2017).

URL http://empowerproject.eu

[4] E. Graham-Rowe, S. Skippon, B. Gardner, C. Abraham, Can we reduce car use and, if so, how? A review of available evidence, Transportation Research Part A: Policy and Practice 45 (5) (2011) $401-$ 418. doi:http://dx.doi.org/10.1016/j.tra.2011.02.001.

[5] A. Hayden, M. Tight, M. Burrow, Is reducing car use a utopian vision?, Transportation Research Procedia 25 (Supplement C) (2017) 3944 - 3956. doi:https://doi.org/10.1016/j.trpro.2017.05.335.

[6] S. Bamberg, S. Fujii, M. Friman, T. Garling, Behaviour theory and soft transport policy measures, Transport Policy 18 (1) (2011) 228-235. doi:http://dx.doi.org/10.1016/j.tranpol.2010.08.006.

[7] L. Eriksson, J. Garvill, A. M. Nordlund, Acceptability of single and combined transport policy measures: The importance of environmental and policy specific beliefs, Transportation Research Part A: Policy and Practice 42 (8) (2008) 1117 - 1128. doi:http://dx.doi.org/10.1016/j.tra.2008.03.006.

[8] M. Kalter, Vaker op de fiets?: effecten van overheidsmaatregelen (Dutch) [More often by bike?: effects of government measures], Tech. rep., Kennisinstituut voor Mobiliteitsbeleid (Oct 2007).

[9] R. Oldenziel, M. Emanuel, A. Albert de la Bruheze, F. Veraart, Cycling Cities: The European Experience: Hundred Years of Policy and Practice, Foundation for the History of Technology, 2016.

[10] J. Dekoster, U. Schollaert, European Commission. Directorate-General for Environment, Nuclear Safety, and Civil Protection, Cycling: The Way Ahead for Towns and Cities, EDC collection, Office for Official Publications of the European Commission, 2000.

[11] J. van Hoogdalem, Fietsen als medicijn. (Dutch) [Cycling as medicine], De Fietsersbond, Utrecht, The Netherlands, 2009, [Online; accessed March 22, 2018].

URL http://media.fietsersbond.nl.s3.amazonaws.com/documenten/fietsenalsmedicjin.pdf

[12] P. Oja, S. Titze, A. Bauman, B. de Geus, P. Krenn, B. Reger-Nash, T. Kohlberger, Health benefits of cycling: a systematic review, Scandinavian Journal of Medicine \& Science in Sports 21 (4) (2011) 496-509. doi:http://dx.doi.org/10.1111/j.1600-0838.2011.01299.x.

[13] R. Buehler, J. Pucher, International overview: cycling trends in Western Europe, North America and Australia, in: R. Buehler, J. Pucher (Eds.), City Cycling, MIT Press, Cambridge/London, 2012, pp. $9-30$.

[14] J. Pucher, R. Buehler, M. Seinen, Bicycling renaissance in North America? An update and re-appraisal of cycling trends and policies, Transportation Research Part A: Policy and Practice 45 (6) (2011) 451 - 475. doi:https://doi.org/10.1016/j.tra.2011.03.001.

[15] L. Harms, L. Bertolini, M. te Brommelstroet, Spatial and social variations in cycling patterns in a mature cycling country exploring differences and trends, Journal of Transport \& Health 1 (4) (2014) 232 - 242. doi:https://doi.org/10.1016/j.jth.2014.09.012.

[16] J. Larsen, The making of a pro-cycling city: Social practices and bicycle mobilities, Environment and Planning A 49 (4) (2017) 876-892. doi:10.1177/0308518X16682732.

[17] D. Privitera, Towards a competitive sustainable city: Cycling as an opportunity, in: K. D. Thomas (Ed.), Handbook of Research on Sustainable Development and Economics, IGI Global, Hershey, PA, USA, 2015, Ch. 2, pp. 20-36.

[18] Hof, T., Fioreze, T., Wijn, R., Thomas, T., Huang, A., Cremers, A., Systematic review of positive interventions for sustainable urban mobility behaviour change. EMPOWER Deliverable D1.1, Tech. rep., EMPOWER project (Dec 2015).

[19] LimeSurvey, Limesurvey, [Online; accessed March 22, 2018] (2017).

URL https: //www. limesurvey . org 
[20] Dutch Central Bureau of Statistics, Fietsen naar het werk populair bij kleine afstanden 2007. (Dutch) [Cycling to work is popular within short distances], [Online; accessed March 22, 2018] (2007).

URL http://cbs.nl/nieuws/2008/38/fietsen-naar-het-werk-populair-bij-kleine-afstanden

[21] Geurs, K.T. and Zaalberg, A. and van Trijp, S.M.A., Nulmeting quickscan mobiliteit. (Dutch) [Baseline quickscan mobility], Tech. rep., Universiteit Twente, Centre for Transport Studies (Feb 2011).

[22] E. Heinen, K. Maat, B. van Wee, The role of attitudes toward characteristics of bicycle commuting on the choice to cycle to work over various distances, Transportation Research Part D: Transport and Environment 16 (2) (2011) 102 - 109. doi:http://dx.doi.org/10.1016/j.trd.2010.08.010.

[23] C. Osgood, G. Suci, P. Tannenbaum, The Measurement of Meaning, Illini Books, IB47, University of Illinois Press, 1957.

[24] S. Deterding, M. Sicart, L. Nacke, K. O'Hara, D. Dixon, Gamification: Using game-design elements in non-gaming contexts, in: CHI '11 Extended Abstracts on Human Factors in Computing Systems, ACM, New York, NY, USA, 2011, pp. 2425-2428. doi:http://doi.acm.org/10.1145/1979742.1979575.

[25] Dutch Central Bureau of Statistics, CBS Statline (database), [Online; accessed March 22, 2018] (2017). URL http://statline.cbs.nl

[26] M. Hamer, Y. Chida, Active commuting and cardiovascular risk: A meta-analytic review, Preventive Medicine 46 (1) (2008) 9 - 13. doi:https://doi.org/10.1016/j.ypmed.2007.03.006.

[27] P. Gordon-Larsen., J. Boone-Heinonen, S. Sidney, B. Sternfeld, D. Jacobs, C. Lewis, Active commuting and cardiovascular disease risk: The CARDIA study, Archives of Internal Medicine 169 (13) (2009) 1216-1223. doi:10.1001/archinternmed.2009.163.

[28] L. B. Andersen, Active commuting is beneficial for health, BMJ 357. doi:https://doi.org/10.1136/bmj.j1740.

[29] S. Park, L. Rink, J. Wallace, Accumulation of physical activity leads to a greater blood pressure reduction than a single continuous session, in prehypertension, Journal of Hypertension 24 (9) (2006) 1761 - 1770. doi:https://doi.org/10.1097/01.hjh.0000242400.37967.54.

[30] P. Chen, J. Zhou, F. Sun, Built environment determinants of bicycle volume: A longitudinal analysis, Journal of Transport and Land Use 10 (1). doi:http://dx.doi.org/10.5198/jtlu.2017.892.

[31] B. Snizek, T. A. S. Nielsen, H. Skov-Petersen, Mapping bicyclists experiences in Copenhagen, Journal of Transport Geography 30 (2013) 227 - 233. doi:https://doi.org/10.1016/j.jtrangeo.2013.02.001.

[32] C. A. Celis-Morales, D. M. Lyall, P. Welsh, J. Anderson, L. Steell, Y. Guo, R. Maldonado, D. F. Mackay, J. P. Pell, N. Sattar, J. M. R. Gill, Association between active commuting and incident cardiovascular disease, cancer, and mortality: prospective cohort study, BMJ 357. doi:https://doi.org/10.1136/bmj.j1456.

[33] E. Ben-Elia, D. Ettema, Changing commuters behavior using rewards: A study of rush-hour avoidance, Transportation Research Part F: Traffic Psychology and Behaviour 14 (5) (2011) $354-368$. doi:https://doi.org/10.1016/j.trf.2011.04.003.

[34] A. Presslee, T. W. Vance, R. A. Webb, The effects of reward type on employee goal setting, goal commitment, and performance, The Accounting Review 88 (5) (2013) 1805-1831. doi:https://doi.org/10.2308/accr-50480.

[35] V. A. Shaffer, H. R. Arkes, Preference reversals in evaluations of cash versus non-cash incentives, Journal of Economic Psychology 30 (6) (2009) 859 - 872. doi:https://doi.org/10.1016/j.joep.2009.08.001.

[36] J. M. Nolan, P. W. Schultz, R. B. Cialdini, N. J. Goldstein, V. Griskevicius, Normative social influence is underdetected, Personality and Social Psychology Bulletin 34 (7) (2008) 913-923. doi:http://dx.doi.org/10.1177/0146167208316691.

[37] M. J. Handgraaf, M. A. V. L. de Jeude, K. C. Appelt, Public praise vs. private pay: Effects of rewards on energy conservation in the workplace, Ecological Economics 86 (2013) 86 - 92. doi:http://dx.doi.org/10.1016/j.ecolecon.2012.11.008. 